\title{
Dolphins, diatoms and sea dragons join census of all known marine life
}

Near-complete tally lists more than 220,000 species and deletes 190,400 duplicates.

\section{Daniel Cressey}

\section{March 2015}

Taxonomists undertaking the daunting task of compiling a list of every species in the sea say that there are 228,445 known marine organisms. The team from the World Register of Marine Species (WoRMS) has eliminated 190,400 previously listed species, because they were duplicate identities.

WoRMS, hosted by the Flanders Marine Institute in Belgium, has more than 200 editors around the world combing through the published literature to tally what lives under the waves. In its latest update, published on 12 March, the organization said that it had added 1,451 creatures in 2014 alone. Jan Mees, the director of the Flanders Marine Institute and WoRMS co-chair, says that after a decade of work, the team has "nearly completed the inventory of all marine organisms that have ever been seen and described". The world's oceans are thought to contain somewhere between 700,000 and 1 million eukaryote species, however, so WoRMS has plenty more work to do.

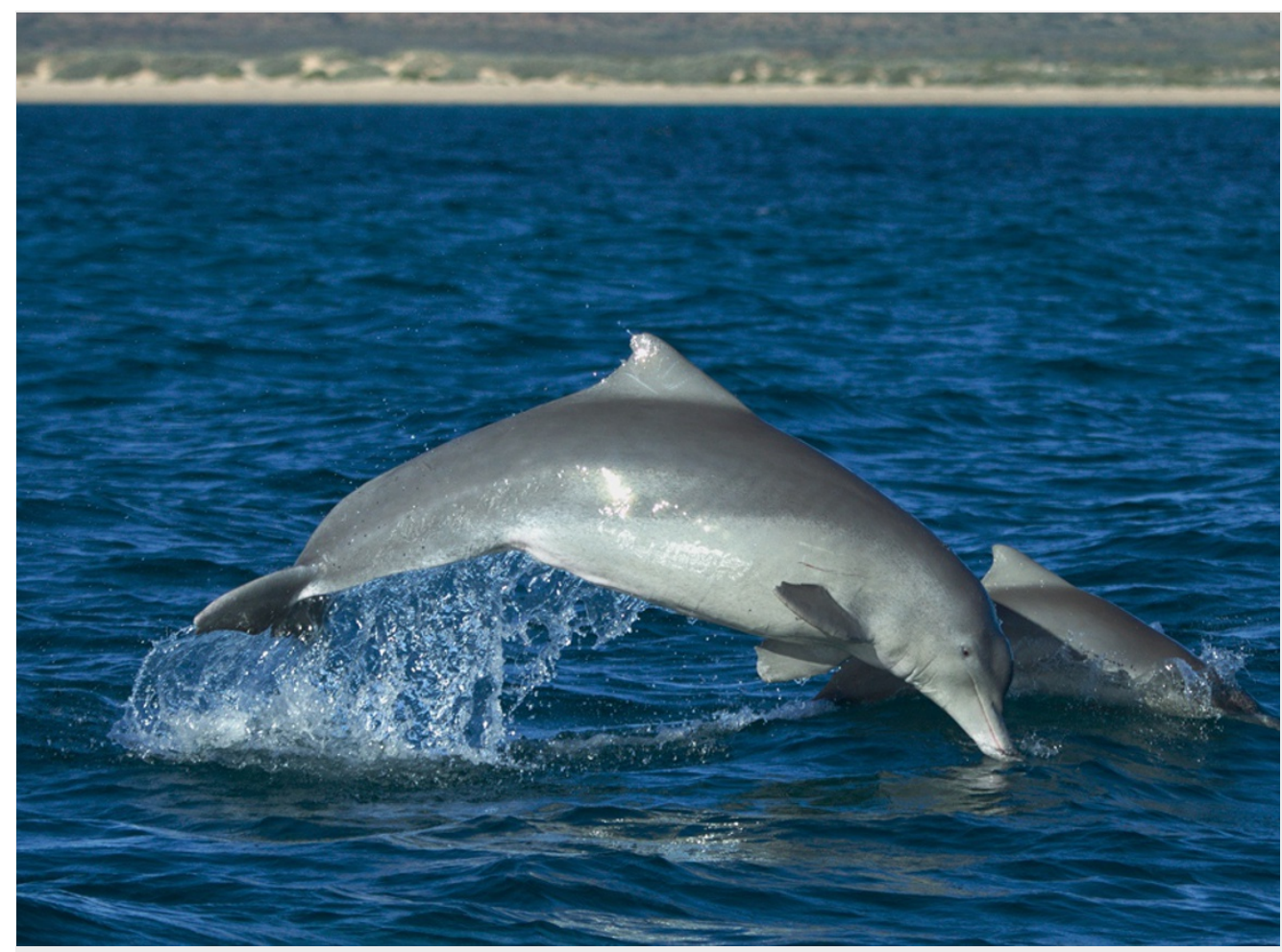

WoRMS Photo Gallery/Robert Pitman

Among the additions since 2008 are the Australian humpback dolphin (Sousa sahulensis). Originally proposed as a separate species in 2013 on the basis of skull and tissue analysis ${ }^{1}$, this animal was formally named last year ${ }^{2}$.

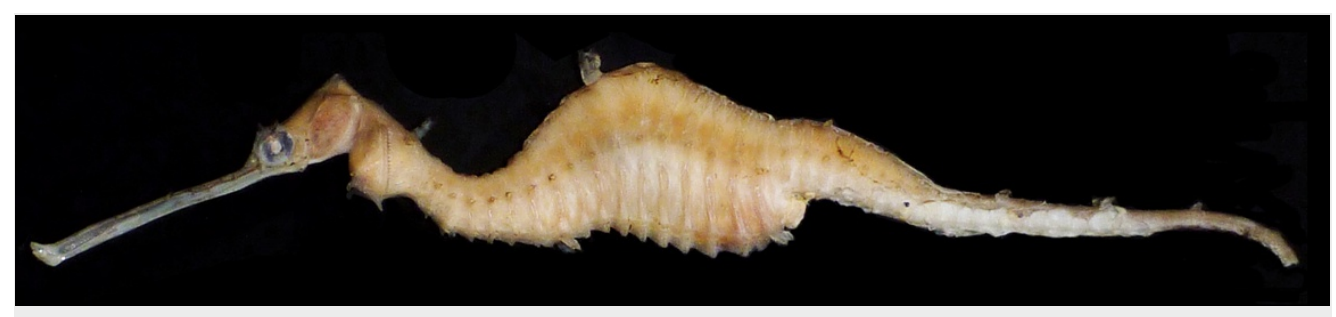

Josefin Stiller, Nerida WIIson and Greg Rouse. 
The third species of sea dragon ever to be identified lives off the coast of Western Australia and was identified by researchers from the Western Australian Museum in Perth and the Scripps Institution of Oceanography in La Jolla, California. The team was investigating a museum specimen presumed to be one of the two previously known species until their DNA-sequencing work suggested otherwise ${ }^{3}$.

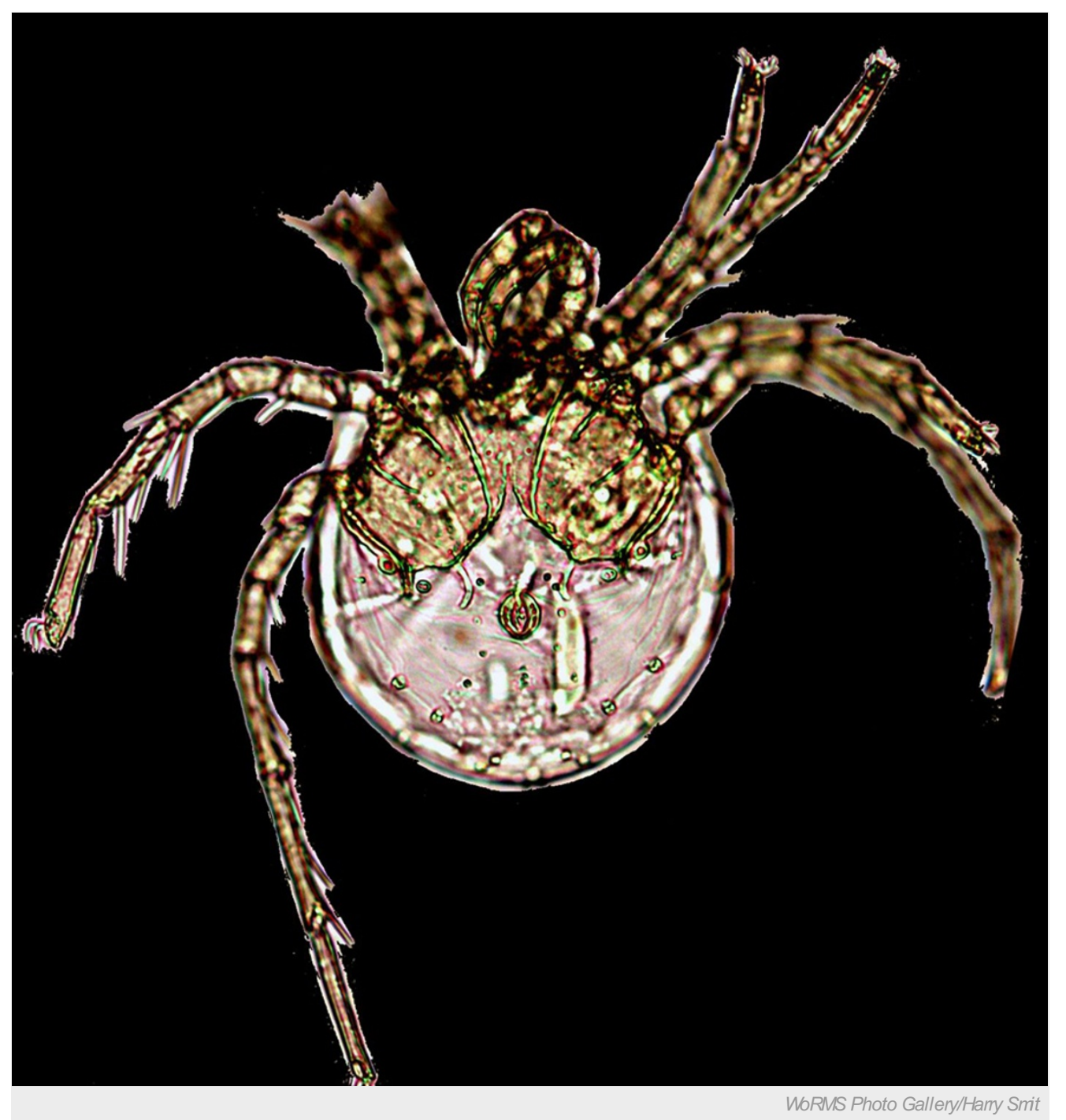

Another species hailing from last year is the 'Jennifer Lopez' mite. Collected from a coral reef 70 metres below the surface off Puerto Rico, Litarachna lopezae, "is named after the famous Puerto Rican singer Jennifer Lopez", reported biologist Vladimir Pešić of the University of Montenegro in Podgorica, and his colleagues ${ }^{4}$. 


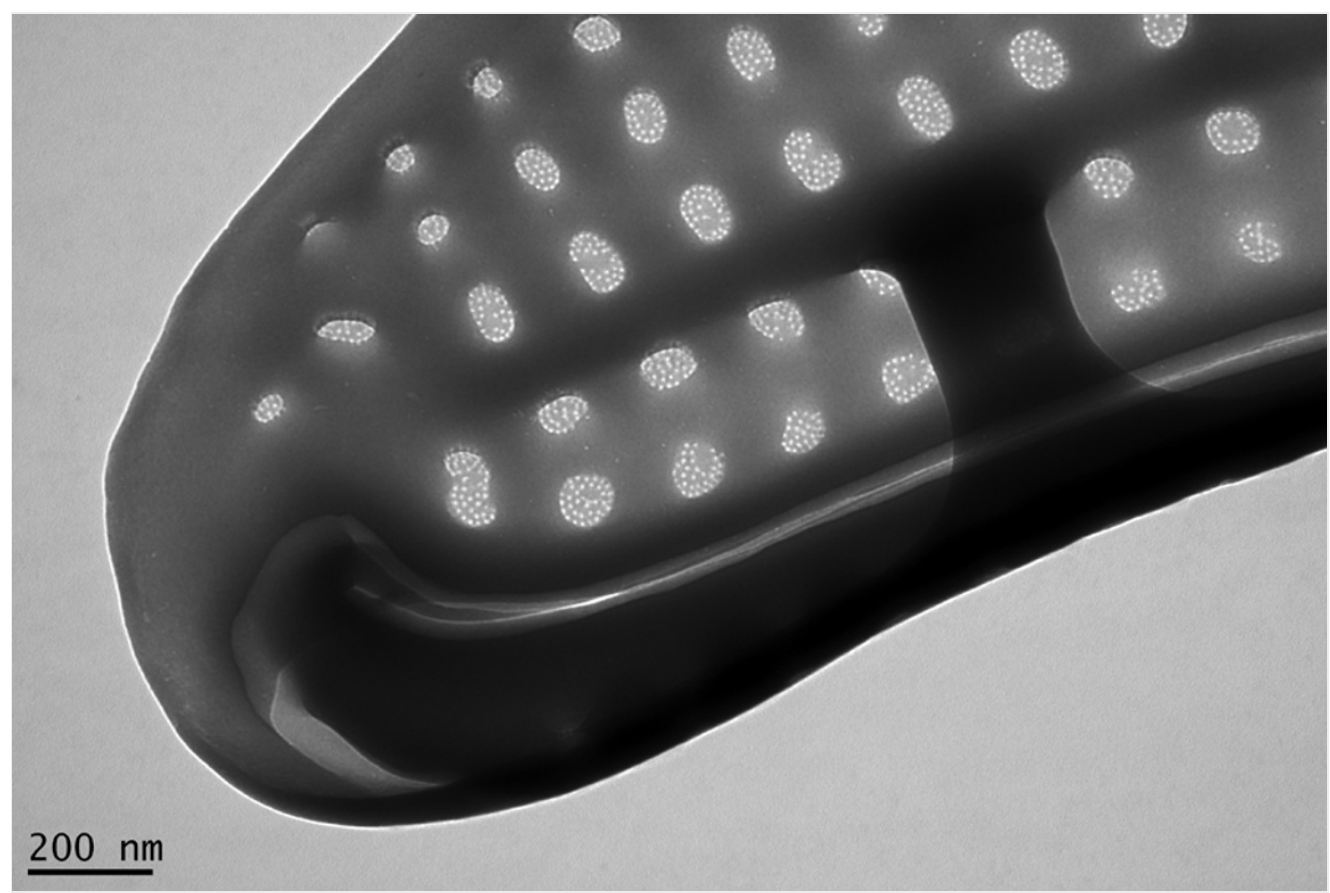

WoRMS Photo Gallery/Nina Lundholm

An even smaller addition to the marine-species list comes in the form of diatom Nitzschia bizertensis. Isolated from a Tunisian lagoon, this alga produces the potent neurotoxin domoic acid 5 .

Although many organisms have been added to the WoRMS database, some have also been eliminated. In 2008 , the team announced that it had found 56,400 aliases in its records.

One animal, the Breadcrumb sponge, had 56 names, which were whittled down to Halichondria panacea. In the latest update, the number of duplicates has tripled. "Most of us were surprised - we knew about the problem of synonyms, but we didn't know the proportion was so high," Mees says. A new record holder for aliases has emerged: the rough periwinkle (Littorina saxatilis). This snail had been described 113 different ways in the scientific literature, leading WoRMS to dub it the champion of taxonomic redundancy.

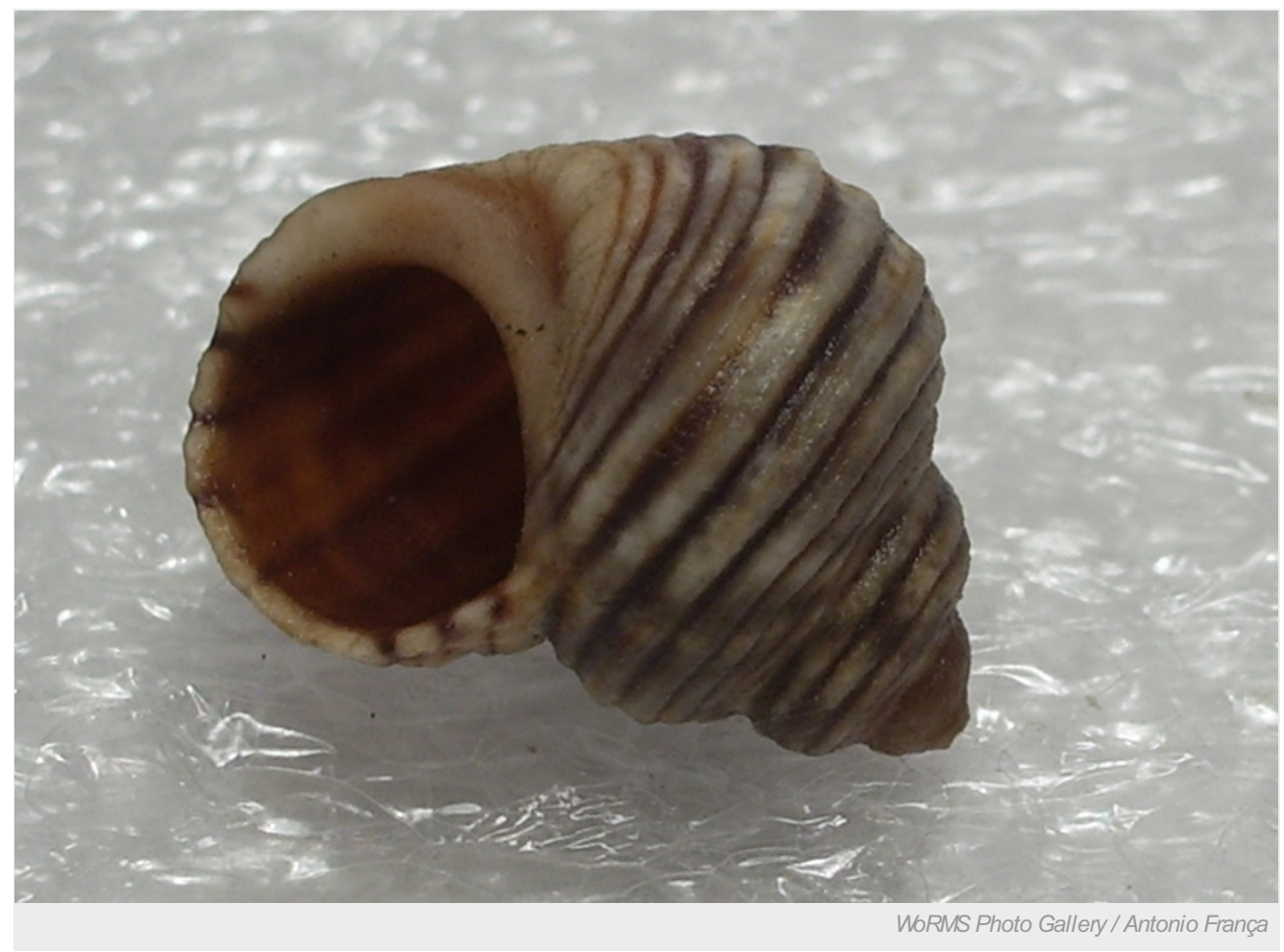

Taxonomists have often complained that their discipline is under appreciated and under funded in recent years. But Mees says WoRMS shows what the community can achieve when it comes together. "It's really a boost for the science," he says. Researchers 
should focus on the lesser explored regions of the world to find new species, he says, including the deep sea and the coastal waters of Africa. But 10,000 marine specimens are thought to be in laboratory jars, waiting to be discovered.

Nature | doi:10.1038/nature.2015.17094

\section{References}

1. Mendez, M. et al. Mol. Ecol. 22, 5936-5948 (2013).

2. Jefferson, T. A. \& Rosenbaum, H. C. Mar. Mamm. Sci. 30, 1494-1541 (2014).

3. Stiller, J., Wilson, N. G. \& Rouse, G. W. R. Soc. Open Sci. 2, 140458 (2015).

4. Pešić, V., Chatterjee, T., Alfaro, M. \& Schizas, N. V. ZooKeys 425, 89-97 (2014).

5. Smida, D. et al. Harmful Algae 32, 49-63 (2014). 